\title{
ADOÇÃO TARDIA: UM PERFIL DISTANTE PARA OS ADOTANTES DO ABRIGO TIA JULIA EM FORTALEZA- CE
}

\section{ARTIGO ORIGINAL}

GOMES, Francisca Eveline Ferreira ${ }^{1}$

SALES, Francélia Maria Almeida ${ }^{2}$

GOMES, Francisca Eveline Ferreira. SALES, Francélia Maria Almeida. Adoção tardia: um perfil distante para os adotantes do abrigo Tia Julia em Fortaleza- CE. Revista Científica Multidisciplinar Núcleo do Conhecimento. Ano 04, Ed. 09, Vol. 01, pp. 67-97. Setembro de 2019. ISSN: 2448-0959, Link de acesso: https://www.nucleodoconhecimento.com.br/ciencias-sociais/adotantes-doabrigo

\section{RESUMO}

Em Fortaleza existe um alto valor numérico de adotantes. Esse número fica ainda maior se comparado, ao valor numérico de crianças aptas a adoção. A pesquisa foi executada junto ao Abrigo Tia Julia em Fortaleza por possui uma faixa etária 0 - 7 anos de idade período que engloba a adoção tardia. $O$ objetivo desse trabalho é entender as dificuldades da adoção tardia no Abrigo Tia Julia. A pesquisa realizada é de natureza qualitativa, bibliográfica e de campo, cujo instrumental de coleta dados é a entrevista com aplicação de formulário semi estruturado. Os dados mostram que o que ocorre em Fortaleza se repete em todo Brasil: um perfil cada vez mais distante

\footnotetext{
1 Pós-graduação em Políticas Públicas e Sociais, Graduação em Serviço Social.

${ }^{2}$ Graduação em Pedagogia, Especialização em Psicopedagogia, Especialização em Educação Comunitária em Saúde, Especialização em Gestão Pedagógica para as Escolas Técnicas do SUS, Especialização em Gestão em Saúde, Especialização em Gestão de Pessoas, Especialização em Docência do Ensino Superior, Mestrado profissional em Educação Profissional em Saúde.
} 
para a maioria dos pretendentes a adoção; os tramites legais envolvidos apontado como burocrático, dificultam a adoção. Conclui-se nesse trabalho que hoje há uma aceitação, maior por parte dos adotantes em relação à adoção tardia. Importante dizer que o resultado dessa pesquisa proporcionou-nos entender as dificuldades da adoção tardia junto ao Abrigo Tia Julia.

Palavras-chaves: Criança, abandono, adoção, abrigo Tia Julia.

\section{INTRODUÇÃO}

Essa pesquisa traz para discussão a adoção tardia no município de Fortaleza, Estado do Ceará. Segundo Levizon (2009, p.43) adoção tardia "[...] é aquela que ocorre com crianças com mais de três anos de idade".

A escolha pelo tema adoção tardia deu-se a partir de reportagens sobre a adoção tardia veiculada pela mídia televisiva, que demonstravam um índice elevado de crianças e adolescentes a procura de pais, para compor e ocupar um lugar que antes era inexistente ou acrescentar a família, com crianças que por motivos diversos, ainda não tiveram ou esperam por um lar.

Outro elemento influenciador da escolha da temática foi às estatísticas referentes à adoção tardia, que mostram o alto desnível referente à quantidade numérica dos adotantes, que é bem superior à quantidade numérica de crianças aptas a adoção. Nos informes de Bandeira (2014) no país em 2014 havia mais de 31,6 mil pretendentes a pais e mães e cerca de 5,5 mil crianças disponíveis para adoção. Contudo Abreu (2002, p.131) aponta que "o número de adoções feitas anualmente não é suficiente para absorver o número de crianças aptas a serem adotadas".

Importa dizer ainda que na medida em que se buscava conhecer mais sobre a temática, percebeu-se a pouca literatura específica disponível sobre adoção. Alguns filmes e livros tratam o assunto de forma lúdica, cujo conteúdo mergulha em uma fantasia que se distancia da realidade, colocando ainda mais a adoção tardia como 
um tema pouco discutido, e expondo-a de forma negativa "[...] encoberta de silêncios, alimentada por mitos e fantasia do senso comum" (VARGAS, 2013 p.17).

Abre-se um parêntese para dizer que se defende que a adoção deve ser mostrada de forma fidedigna, de acordo com sua realidade, independente do meio de comunicação no qual o assunto é veiculado. Desse modo, pode-se empreender o debate e o esclarecimento sobre a adoção, desmistificando-a para grande parte da população, podendo até contribuir para que haja um acréscimo nas adoções afetivas futuras.

Esse estudo tem como objetivo principal, o entendimento das dificuldades da adoção tardia. Nesse sentido relatar o caminho a ser percorrido em meio aos tramites legais para adoção - dos primeiros passos a conclusão judicial; à chegada das crianças a serem adotadas ao Abrigo Tia Júlia, e os trabalhos desenvolvidos pelas Assistentes Sociais nessa instituição. A inserção nessa realidade acredita-se trará para pesquisadora uma aproximação para saber quais as dificuldades encontradas pelo Abrigo Tia Júlia para a adoção tardia.

Foi utilizada a pesquisa qualitativa dentro do processo de categorização. Para um melhor domínio do assunto em discussão sendo articulado e dialogado com autores conhecedores do tema, através de suas obras bibliográficas, também será utilizado uma pesquisa de campo com o intuito de haver uma aproximação com a realidade do objeto da pesquisa. Para a pesquisa de campo utilizou como instrumental de coleta de dados, entrevistas semi estruturadas com os profissionais do abrigo Tia Júlia que atuam e tem contato direto com as crianças.

Mas falar sobre esse tema remete voltar na história, conhecer a trajetória pelo caminho da adoção, portanto o tópico um, aborda a adoção no contexto histórico dissertando sobre o abandono de crianças na antiguidade; ocorrências reforçadas com prática da roda dos enjeitados que se iniciou na Europa e foi reproduzida em todo o mundo. Trazse como destaque o código civil brasileiro de 1916, que aprovou uma das primeiras leis para adoção, com as condicionalidades para todos os adotantes, e concluindo com o código de menores no Brasil e seu enquadramento para com os jovens que cometessem algum ato infracional. 
No tópico dois expõe-se à adoção após a criação do Estatuto da Criança e do Adolescente (ECA) de 1990, instituto garantidor dos direitos da criança e do adolescente. $\mathrm{O}$ tópico três explana a adoção; os motivos que a maioria dos adotantes tem para escolha pela adoção; as questões sociais que envolvem o tema. Também foi divulgado dados estatísticos e comparativos da quantidade numéricas dos pretendentes a adoção $\mathrm{x}$ a quantidade numérica das crianças aptas a adoção, no Brasil e em Fortaleza, informações também sobre o Abrigo Tia Julia, bem como, o resultado da entrevista com as assistentes sociais, através do qual se conheceu o trabalho realizado por essas profissionais dentro da instituição e a metodologia utilizada no projeto.

\section{ADOÇÃO: CONTEXTO HISTÓRICO}

Faz-se aqui um recorte na história mostrando os principais fatos importantes com suas evoluções e o início dessa trajetória, na antiguidade, os ${ }^{[3]}$ primeiros povos a praticar a adoção foram os hindus, egípcios, persas, hebreus, gregos, e romanos. A bíblia relata a história de Moises, "filho das águas" cuja mãe logo após seu nascimento, visto que o rei do Egito havia mandado matar todos os primogênitos homens nascidos dos hebreus, o deixou no rio para não morrer. "A criança foi encontrada pela filha do Faraó, ao banhar-se no rio, que o retirou das águas e decidiu criá-lo passando a ser tratado como seu filho" (WEBER, 2010 p.26).

Conta-se na história que, na ${ }^{[4]}$ Roma antiga os adotantes tinham que ter acima de 60 anos, quem tivesse filhos biológicos não possuía esse direito. Os imperadores da época também adotavam, assim, eles escolhiam seus sucessores. Com o tempo a adoção passou a ser usada como ato de consolo para casais que não podiam ter filhos.

Já na idade média houve uma queda na adoção através dos discursos da igreja católica que não apoiava a adoção, pois "[...] suspeitava também que esta servia “[...] para legitimar filhos bastardos, tidos fora do casamento e trazidos por maridos infiéis para o sagrado seio do matrimônio" (ABREU, 2002 p.22). 
Lisboa (1996) relata que o real interesse da igreja católica em defender esse pensamento era:

Tanto a igreja como a nobreza eram hostis a adoção: as famílias que morriam sem descendência deixavam seus bens para as abadias, congregações religiosas ou os tinham confiscados pelos senhores feudais. Um filho era um concorrente a ser evitado. A adoção desapareceu neste período (LISBOA, 1996, p.22).

Weber (2010) lembra ainda que o código de Hammurabi era muito próximo das leis atuais com o princípio dos cuidados das crianças, ao escrever que "a sociedade mesopotâmia do II milênio A.C. autorizava uma mulher estéril a cuidar dos filhos nascidos de seu marido, com outra mulher que ela própria escolheria". Visto que o intuito dessa adoção era garantir a descendência, é possível dizer que o cuidado ao filho de outra mulher mostra o afeto não biológico.

O autor supracitado destaca que foi graças ao código de Napoleão, que a adoção começava a engatinhar para um novo rumo, que "[...] visava basicamente aos interesses do adotado, ou seja, aos interesses da criança que não tinha uma família" (WEBER, 2010 p.46).

Nesse sentido Vargas (2013 p.19) escreve: Napoleão Bonaparte, cuja esposa Josefina havia se tornado estéril procurou garantir, através do Código Civil Francês, todos os direitos aos filhos adotivos, inclusive os de sucessão.

No entanto, Weber (2010) diz que mesmo depois da criação do código Napoleônico a maioria dos países europeus, com exceção da Inglaterra, construiu sua lei baseada nos códigos Romano que trazia outra visão do que era adoção. Por exemplo, ${ }^{[5]}$ na França em 1804 se estipulou a idade mínima para 50 anos como condicionamento para os pretendentes a adoção.

Weber (2010) também menciona que desde século XIX a adoção tem origem ligada à caridade e a mão de obra doméstica e barata. Nesse mesmo século nos Estados Unidos às mães que eram solteiras tinham o convívio com os filhos só nos finais de semanas, pois na semana as crianças viviam em abrigos. 
Outra cultura sobre adoção teve destaque no período da Primeira Grande Guerra, no qual "os países de direito anglo-saxão passaram a usar a adoção legal a fim proverem de pais os numerosos órfãos de guerra, julgados pela sociedade como filhos heróis" (VARGAS, 2013 p.20).

Depois desse fato, parece que após a Primeira Guerra Mundial, por causa do grande número de crianças órfãs e abandonadas a adoção começou realmente a adquirir um sentido mais social, voltando-se ao interesse da criança (WEBER, 2010).

Já no Brasil, com a colonização tivemos influência direta de outras culturas. Marcílio (2006 p.12) relata que:

[...] o ato de expor os filhos foi introduzido no país pelos brancos europeus - o índio não abandonava os próprios filhos. Aí está o outro lado perverso da colonização. Como consequência, os portugueses introduziram leis instituições e comportamentos de assistência e de proteção à infância abandonada, nos moldes do que havia adotado desde tempos medievais.

Desde modo, concorda-se com Weber (2010) quando coloca que cada cultura vem assumindo, ao longo dos períodos históricos, posturas diferenciadas em relação à adoção, que sempre estão relacionadas ao contexto sócio-político, econômico e religioso da época (p.24).

\subsection{RODA DOS ENJEITADOS}

De acordo com leitura bibliográfica nos períodos Colonial e Imperial crianças legítimas e ilegítimas eram abandonadas em diversos locais urbanos, na tentativa dos pais de livrarem-se do filho indesejado, não amado ou ilegítimo (surgido de uma traição) (WEBER, 2010). Dessa forma não havia nenhuma obrigatoriedade perante aquelas crianças, e assim, os pais biológicos "resolviam o problema". "Para estas crianças denominadas enjeitadas, desvalidas ou expostas, foi copiado o modelo europeu: a Roda dos Expostos ou Roda dos Enjeitados, um dispositivo de madeira que permitia o abandono anônimo de bebês" (WEBER, 2010 p.49).

Marcílio (2006, p.57) esclarece que, 
O nome Roda - dado por extensão à casa dos expostos - provém do dispositivo de madeira onde se depositava o bebê. De forma cilíndrica e com uma divisória no meio, esse dispositivo era fixado no muro ou na janela da instituição. No tabuleiro inferior da parte externa, o expositor colocava a criancinha que enjeitava, girava a Roda e puxava um cordão com uma sineta para avisar à vigilante ou Rodeira - que um bebê acabara de ser abandonado, retirando-se furtivamente do local, sem ser reconhecido. A origem desses cilindros rotatórios vinha dos átrios ou vestíbulos de mosteiros e de conventos medievais, usados para outros fins, como o de evitar o contato dos religiosos com o mundo exterior.

Apesar dos abandonos dos órfãos ocorrerem na calada da noite era de conhecimento de toda sociedade a existência da roda dos enjeitados. "Em 1838, Lamartine defende a Roda na câmara, apresentando-a como a melhor maneira de preservar a honra das famílias, e contra os parlamentares malthusianos, temerosos da proliferação dos pobres" (WEBER, 2010 p.46).

Diante da definição do que a Roda dos Enjeitados significava para a época, ela passa a ser também considerada como responsável pela alta dos abandonos (67 mil em 1809, $121 \mathrm{em} \mathrm{1835).} \mathrm{As} \mathrm{rodas} \mathrm{foram} \mathrm{gradualmente} \mathrm{sendo} \mathrm{fechados} \mathrm{e} \mathrm{"[...]} \mathrm{em} 1860$ apenas 25 asilos ainda dispunham delas. E no mesmo ano foram inteiramente suprimidas por uma circular ministerial passando a não mais existir e sua prática se tornou proibida" (WEBER, 2010 p.46).

No Brasil também existia a Roda dos Enjeitados e demorou um pouco mais sua extinção. De acordo com Orlandi apud Weber, (2010), diz que entre 1861 e 1874, deram entrada na Roda 8.086 crianças, das quais 3.545 morreram.

Importante sublinhar que nem todas as crianças entregues à Roda dos Enjeitados permaneciam internadas. Muitas delas eram criadas por "famílias criadeiras ou negras de aluguel" (ARANTES, 1991 p.194).

\subsection{CÓDIGO CIVIL DE 1916 NO BRASIL}

De acordo com Dutra e Maux, citados por Paganine (2013) era comum haver no interior da casa das pessoas abastados filhos de terceiros, chamados filhos de 
criação. Essa prática era vista de forma natural tanto pela família biológica como pela família de criação.

A situação no interior da família não era formalizada, servindo sua permanência como oportunidade de possuir mão de obra gratuita e, ao mesmo tempo, prestar auxílio aos mais necessitados, conforme pregava à igreja (PAGANINE, 2013 p.02).

O tema adoção trazia muita discussão, e para argumentar que a inclusão da adoção neste código foi motivo de acirrada polêmica, e a mesma obteve lugar graças à autoridade e pertinácia de Clóvis Beviláqua. Dando mais peso a efetivação para vigorar a lei, tanto que "[...] sua argumentação teve acolhida porque foi sustentada por referências ao direito romano e pela afirmação de que figuraria nos códigos de quase todas as nações culturas (REICHERT apud WEBER, 2010 p.50).

Conforme a Lei $n . \stackrel{\circ}{ } 3.071$ de 01/01/1916

Art. 368. Só os maiores de cinquenta anos, sem prole legítima, ou legitimada, podem adotar.

Art. 369. O adotante há de ser, pelo menos, dezoito anos mais velho que 0 adotado.

Art. 370. Ninguém pode ser adotado por duas pessoas, salvo se forem marido e mulher.

Art. 371. Enquanto não der contas de sua administração, e saldar o seu alcance, não pode o tutor, ou curador, adotar o pupilo, ou o curatelado.

Art. 372. Não se pode adotar sem o consentimento da pessoa, debaixo de cuja guarda estiver o adotando, menor ou interdito.

Art. 373. O adotado, quando menor, ou interditado dera desligar-se da adoção no ano imediato ao que cessar a interdição, ou menoridade.

Art. 374. Também se dissolve o vínculo da adoção:

I- Quando as duas partes convierem.

II - Quando adotado cometer ingratidão contra o adotante.

Art. 375. A adoção far-se-á por escritura pública, em que se não admite condição, nem termo. 
Art. 376. O parentesco resultante da adoção (artigo 336) limita-se ao adotante e ao adotado, salvo quanto aos impedimentos matrimoniais, a cujo respeito se observará o disposto no art.183, no s. III e V.

Art. 377. A adoção produzirá os seus efeitos ainda que sobrevenham filhos ao adotante, salvo se, pelo fato do nascimento; ficar provado que o filho estava concebido no momento da adoção.

Art. 378. Os direitos e deveres que resultam do parentesco natural não se extinguem pela adoção, exceto o pátrio poder, que será transferido do natural para o adotivo (LACERDA apud WEBER, 2010 p.51).

Mesmo depois do surgimento da lei 3.071, que era vista como algo positivo em prol de mais possibilidades de adoções, e pelo Código Civil brasileiro, elas assemelhavamse àquelas ditadas pelo Código Napoleônico. Eram excessivamente rígidas e, consequentemente, isto acabava se tornando muito burocrático e lento, pois "[...] dificultava o seu uso social. "Somente podiam adotar os maiores de 50 anos, sem filhos legítimos, ou ilegítimos", deixando boa parte da população fora do perfil da lei (WEBER, 2010 p.51).

\subsection{CÓDIGO DE MENORES NO BRASIL}

A partir do ano de 1927, é criado o Código de Menores brasileiro (o primeiro da América Latina). Para Weber (2010 p.51) ele apresenta definições de abandono e delinquência, e suspensão de pátrio poder, diferença entre menor abandonado e delinquente, e uma dupla definição de abandono - físico e mental.

Um caso que ocorreu no Brasil aconteceu com um engraxate de 12 anos se irritou, em 1926, com um cliente que se recusou a pagar por um serviço feito nas ruas do Rio de Janeiro. O menino Bernardino teria atirado tinta nessa pessoa, o que acabou rendendo a ele quatro semanas de prisão. Na cela, o garoto foi brutalmente violentado por 20 adultos, segundo notícia do Jornal do Brasil. Os repórteres do jornal encontraram o menino na Santa Casa "em lastimável estado" e "no meio da mais viva indignação dos seus médicos". A veiculação do caso causou uma polêmica forte na época e iniciou uma discussão pública que chegou às altas rodas do Congresso e também do Palácio do Catete, a então sede do governo federal. O presidente Washington Luís escolheu o dia da Criança (12 de outubro) para assinar o Código de Menores. Foi à primeira legislação específica para infância e adolescência no País. Uma das principais decisões foi a de que apenas 
os maiores de 18 anos de idade poderiam ser criminalmente responsabilizados e encarcerados (BRASIL, 2015 p.02).

Depois do caso da criança de 12 anos que ocorreu em 1926, nela relata a forma no qual era tratada ilegalmente as crianças, nessa época não existiam leis punitivas para ressocialização de criança e do adolescente, todos que cometiam algum ato infracional eram considerados delinquentes. Assim, compreende-se segundo a definição de Marcílio (2006, p.224) que esse Código de Menores:

Foi montado exclusivamente para o controle da infância e da adolescência abandonadas e delinquentes. Art. 10 menor, de um e outro sexo, abandonado ou delinquente, que tiver menos de 18 anos de idade, será submetido pela autoridade competente às medidas de assistência e proteção contidas neste "Código". Este Código de Menores não trouxe nenhuma contribuição á questão da adoção e nem contribuiu para diminuir o número de crianças abandonadas no país, apenas enfatizou a institucionalização de crianças como uma forma de proteção à infância.

Percebe-se, diante dos fatos apresentados, que o código de menores foi criado com o intuito de enquadrar a criança e o adolescente, que aos olhos do Estado viessem a cometer alguma infração seria punido, não com o objetivo protegê-lo ou disponibilizar direitos, e sim como forma de condicionar o jovem. Com a criação do código de menores no Brasil cria-se o posicionamento do Estado para institucionalização de crianças e adolescentes.

\section{ESTATUTO DA CRIANÇA E DO ADOLESCENTE (ECA)}

Junto com Constituição Federal de 1988 surgem os princípios que regem o Estatuto da Criança e do Adolescente (ECA) se tornando lei e obrigação à garantia dos direitos da criança e do adolescente em sua plenitude (LOPES, 2015).

De acordo com o artigo 227 da Constituição Federal de 1988, sendo agora de absoluta prioridade a criança e o adolescente, que a partir daí passaram a ter todos os direitos inerentes à pessoa humana, um sujeito de direitos, com proteção integral, o Estado prometeu prevenção de direitos fundamentais, respeito à condição peculiar de pessoa em desenvolvimento nele vem distrito (LOPES, 2015). 
Art. 227 É dever da família, da sociedade e Estado assegurar à criança, ao adolescente e ao jovem, com absoluta prioridade, o direito à vida, à saúde, à alimentação, à educação, ao lazer, à profissionalização, à cultura, à dignidade, ao respeito, à liberdade e à convivência familiar e comunitária, além de colocá-los a salvo de toda forma de negligência, discriminação, exploração, violência, crueldade e opressão (LOPES, 2015 p.109).

Depois dos fatos expostos, mostrando a trajetória dentro da história percorrida no campo da adoção, chega-se em 1990, especificamente em 13/07/1990, data na qual foi criada a lei $n^{\circ} 8.069 / 90$, surgindo assim, o Estatuto da Criança e do Adolescente (ECA).

A concepção que sustenta o ECA é a Doutrina de Proteção Integral, defendida pela ONU com base na Declaração Universal dos Direitos da Criança, a firma o valor intrínseco da criança como ser humano iniciando ainda no período embrionário (VARGAS, 2013 p.24).

São revogadas as leis anteriores, inclusive o Código de Menores de 1979. A única forma de adoção prevista "é agora irrevogável e transfere o pátrio poder dos pais biológicos para a família adotante" (ABREU, 2002 p.28).

Art. 43 - A adoção será deferida quando apresentar reais vantagens para 0 adotando e fundar-se em motivos legítimos. Frente a essa realidade, a criança passa a não ser mais um objeto para satisfação dos desejos dos adultos que querem ter filhos, pelo contrário ela passou a ser o sujeito de direito à convivência familiar e comunitária (BRASIL, 2005 p.25).

Dessa forma, é visto em primeiro lugar o que melhor atende seu interesse. Devido a isso todo o processo de adoção tem que ser cuidadoso. Com o intuito de mantê-la na família com outros membros familiares, no qual a criança tenha afinidade, a vantagem é que mesmo enfraquecendo vínculos com os pais, ela permaneça no mesmo ambiente familiar, passando a conviver com a família ampliada (BRASIL, 2005).

As transições para o amparo as crianças e adolescentes estão baseada na:

GUARDA Art. 33-Ela regulariza a posse, excepcional, direito de dependente (inclusive previdenciária).

TUTELA Art. 36 - Previa decretação de perda ou suspensão do poder familiar, implicar guarda, não desfaz vínculo familiar. 
ADOÇÃO Art. 39 - Medida excepcional e irrevogável, mínima de 12 anos, salvo sob guarda ou tutela, atribui condição de filho (LOPES, 2015, p.428-429).

Atentamos agora para o art. ㄲo 39 (ECA, 1990) em minucia, que destaca a adoção como um ato excepciona e irrevogável, no qual a criança e o adolescente só poderiam ser adotados após o esgotamento de todas as possibilidades de voltar para sua família natural ou extensa, também é um ato irrevogável, pois uma vez adotada não tem como ser revogada a decisão, não pode ser anulado, nem retificado, adoção legal é para sempre e fica vedado à adoção por procuração se tornando assim, um ato personalíssimo, essas afirmações descreve a adoção como não devolutiva depois de deferida sentença.

Perante $a$ isso, a adoção se faz sempre plena, define-se no art. no 41(ECA, 1990) que "a adoção atribui a condição de filho ao adotado, com os mesmos direitos e deveres, inclusive sucessórios, desligando-o de qualquer vínculo com pais e parentes, salvo os impedimentos matrimoniais" (BRASIL, 2005 p.24). Assim, no Brasil não se admite nem uma distinção entre filhos adotivos e biológicos.

Uma das regras para se iniciar uma adoção estar no art. 42, o adotante pode iniciar uma adoção a partir dos 18(dezoito) anos, hoje o estado civil do adotante não interfere na adoção (Redação dada pela lei $n^{\circ} 12.020$, de 2009). O referido ainda destaca em seus quatro incisos que:

$\S 1^{\circ}$ não podem adotar os ascendentes e os irmãos do adotando.

$\S 2^{\circ}$ para adoção conjunta, é indispensável que os adotantes sejam casados civilmente ou mantenham união estável, comprovada a estabilidade da família.

$\S 3^{\circ} 0$ adotante deve ser, pelo menos dezesseis anos mais velho que 0 adotando.

$\S 4^{\circ}$ os divorciados, os judicialmente separados e os ex - companheiros podem adotar conjuntamente, contanto que acordem sobre a guarda e 0 regime de visitas e desde que o estágio de convivência tenha sido iniciado na constância do período de convivência e que seja comprovada a existência de vínculos de afinidades com aquele não detentor da guarda, que justifiquem a excepcionalidade da concessão. 
Mesmo depois de mostrar várias medidas instituídas pelo Estado, objetivando os direitos universais das crianças e dos adolescentes, ainda ocorrem muitos abandonos e maus tratos e segundo Gonçalves ${ }^{[6]}$, uma pesquisa realizada em Fortaleza mostrou que cerca de 570 crianças e adolescentes vivem em abrigos em Fortaleza. Do total, $12 \%$ estão disponíveis para adoção o que corresponde a 74 meninos e meninas incluídas no Cadastro Nacional de Adoção (CNA). A grande maioria, 496, ainda tem vínculos com a família de origem e espera a justiça definir se voltam para casa dos pais ou de parentes mais próximos ou se vão ser entregues para adoção.

Deste modo, compreende-se que a espera pela decisão judicial, se a criança fica com os pais biológicos ou vai para adoção pode ser longa, pois "a destituição do pátrio poder costuma ser um processo longo". Às vezes, a dificuldade de localização dos pais faz com que as crianças fiquem 'depositadas' em abrigos provisórios e acabem sendo barradas dos vínculos afetivos com sua família natural ou pais adotivos (VARGAS, 2013 p.18).

E mesmo depois de perder totalmente os vínculos familiares, "transformam-se em prisioneiros sociais, ou seja, tornam-se pessoas privadas de liberdade sem terem cometido nenhum delito a não ser, de serem pobres numa sociedade como a nossa" passam a serem abandonados e institucionalizados (VARGAS, 2013 p.18). Esta "criança abandonada e rejeitada por sua mãe biológica passou a ser rejeitada mais uma vez por toda sociedade" (WEBER, 2010 p.67).

De acordo com Lopes (2015 p.21)

[...] atrás de toda história de abandono, fugas, orfandade, exploração e violência, que envolvem crianças e adolescentes, esta à desigualdade social onde populações inteiras vivem em condições precárias resultado do sistema de produção capitalista, sistema esse que é neoliberalista tendo sua característica ser mínimo para o social e máximo para o capital, aumentando assim a desigualdade, pobreza, miséria, enfim tudo faz parte das expressões que compõem a questão social, criando a hegemonia social.

As crianças e adolescentes brasileiros, primeiramente vitimados por questões socioeconômicas advindas de uma política nacional que historicamente vem sendo 
responsável pelo crescimento de desigualdades de toda ordem, são também vitimados por um processo de estigmatização, marginalização e exclusão quando são alijados do direito à família, por consequência, de uma cultura da adoção que privilegia crianças recém-nascidas em detrimento de crianças mais velhas e/ou adolescentes (CAMARGO, 2005).

Ao observar as estatísticas dos dados do Cadastro Nacional de Adoção (CNA) salienta-se que para cada criança na fila, há cinco famílias querendo adotar. O perfil das crianças que os futuros pais sonham, no entanto, é bastante restrito. Sendo um dos principais motivos para alongar o tempo de esperar na fila, e criando um maior tempo das crianças nos abrigos, e quanto mais esse tempo aumenta mais velhas ficam e fora do perfil de escolha dos pretendentes a adoção.

Destaca-se que no art.19 (ECA, 1990) a permanência da criança e do adolescente em programa de acolhimento institucional, não se prolongará por mais "[...] de 02 (dois anos), salvo comprovada a necessidade que atenda ao seu superior interesse". Devidamente fundamentada pela autoridade judiciária (LOPES, 2015 p.426).

\section{ADOÇÃO}

A adoção foi tratada "[...] tradicionalmente como uma ação de mão única, isto é, as agências buscavam crianças que pudessem atender aos anseios de casais que não podiam ter filhos" (WEBER, 2010 p.12).

Depois da criação do Estatuto da Criança e do Adolescente (ECA), a adoção prioriza ao interesse da criança e do adolescente fez com que se buscasse a efetiva busca pelo melhor interesse do menor, dessa forma a "adoção não é apenas a inclusão de uma criança na vida de uma família, mas também e principalmente a inclusão de muitas pessoas na vida de uma criança" (OLIVEIRA, 2014 p. 36-38).

A adoção é uma das formas de parentalidade não biológica regulamentadas pelo Estado, geralmente utilizada por casais que enfrentam uma condição de infertilidade (OTUKA, SCORSOLINI; SANTOS, 2013 p.90). 
Camargo (2005, p.34) lista uma série de fatores que levam um casal a optar pela adoção além da infertilidade ou esterilidade:

a) preencher um vazio causado pela perda de um filho; b) possuir bens e não haver quem deles desfrute ou continue após a morte do casal; c) a busca por um filho para que ele, de alguma forma, mantenha a união conjugal; d) realização de um projeto de vida a dois, que seria casar e ter filhos; e) ser solteiro e estar em busca de passar pela experiência de maternidade/paternidade; f) ser viúvo e buscar evitar a solidão, e; g) escolher o sexo do bebê. O que se percebe é que, nesses casos, a criança vem como uma solução para as expectativas, problemas ou vontades dos adotantes.

Para Reppold (2003, p.40) "investigar o que motivou os pretendentes a adoção a buscar a adoção é de extrema importância, uma vez que os interesses dos mesmos exercem grande influência na qualidade da relação que será estabelecida entre os pais e o filho".

O conceito comum define uma adoção como tardia "se a criança adotada tiver mais de dois anos de idade" (WEBER, 2010 p. 76). A adoção tardia é "considerada especialmente necessária em razão da dificuldade de localização de pretendentes á adoção com perfil adotivo para crianças mais velhas" (OLIVEIRA, 2014 p.71).

Tardia é um adjetivo usado para designar a adoção de crianças maiores. Considera-se maior a criança que já consegue se perceber diferenciada do outro e do mundo, ou seja, a criança que não é mais um bebê, que tem certa independência do adulto para satisfação de suas necessidades básicas [...] Pode acontecer que crianças com dois, três anos ainda não apresentem comportamentos compatíveis com a sua faixa etária, ou seja, não andam sozinhas, não falam ou usam fraldas e a adaptação delas não apresentará características típicas de uma adoção tardia, como as fases de 22 comportamentos agressivos ou regressivos, pelas quais passam a maioria das crianças adotadas a partir dessa idade (VARGAS, 2013 p.69).

Grande parte das famílias inclinadas a adotar tardiamente sofre com medo e desconfiança em relação ao comportamento que será apresentado pelo adotado (CAMARGO, 2005 p.25). 
Um dos preconceitos que envolvem a adoção tardia, segundo anuncia Bethoud (1997) apontam principalmente para o medo do chamado.

"[...] sangue ruim, compreendido como aquele receio que os adotantes têm de que a criança traga consigo" "[...] traços negativos de caráter e temperamento da família biológica, dentre outros preconceitos baseado no senso comum" (BETHOUD, 1997, p.73).

Conforme (OLIVEIRA, 2014 p.59) os tipos de adoção em relação aos pretendentes a adoção são:

- Adoção Biparenteral: adoção pleiteada por dois adotantes necessariamente casados ou conviventes em união estável.

- Adoção Monoprenteral: adoção pleiteada por um único adotante. A lei assegura ao solteiro (a), ao viúvo (a), e ao divorciado (a) o direito de adotar, não lhe sendo necessária a convivência ou mesmo o matrimônio.

- Adoção Unilateral: adoção realizada por um único adotante, que pleiteará a concessão da adoção do filho do outro cônjuge (necessário o vínculo de união estável ou matrimônio, entre o adotante e o genitor do adotado).

Os casais brasileiros que fazem uso dos serviços da justiça para adotar têm preferido por certo tipo de criança: branca, de sexo feminino, saudável e contando menos de 1 ano de vida (ABREU, 2002).O autor ressalta ainda que em Fortaleza, no Abrigo Tia Júlia, não é diferente. A escolha de crianças com esse perfil, diminuem as chances de crianças maiores de 7 até 12 anos de idade de serem adotadas (p.126-127).

Esse é o perfil mais procurado por grande parte dos adotantes, vejamos o que diz o presidente da Associação Nacional de Grupos e Associações de Apoio a Adoção (ANGAAD, p.02):

Entendemos e respeitamos profundamente o desejo destes pais (que querem adotar um bebê, branco e saudável), porém, precisamos traduzir a realidade da criança em situação de abandono que, na maioria das vezes, não preenche o modelo físico idealizado, mas poderá preencher o coração. Estes são esquecidos em instituições, lares e abrigos da sociedade e poderão se tornar filhos queridos e esperados [...] o 
verdadeiro amor de pais e filhos se cultiva e para isso não há idade específica [...].

E quem não se encontra dentro desse quadro tão desejado pelos pretendentes a adoção fica mais difícil de ser adotado. "Mais difícil ainda se torna a adoção quando se trata de grupo de irmãos, de crianças não brancas e/ou portadores de algum tipo de deficiência" (VARGAS, 2013 p.26).

Somado aos itens anteriores às crianças "não adotáveis" possuem um perfil geralmente com mais idade "[...] muitas negras e mulatas, tem encontrado oportunidade de adoção quase que exclusivamente por estrangeiros, através da adoção internacional" (WEBER, 2010 p.67).

Devido à procura pela adoção internacional, a adoção por estrangeiros passou a ser medida excepcional (Art.31 ECA). Considerando o interesse da criança é definida pelo legislador sua permanência no Brasil, a questão é que muitas crianças não estão dentro do perfil brasileiro para adoção. Porém, “a adoção por estrangeiros é admitida unicamente quando a criança não é desejada por nenhum brasileiro" (ABREU, 2002 p.39).

Muitos adotantes reclamam do processo de adoção, cujas dificuldades e 'burocracias', no linguajar dos adotantes, "passam a ser de certa forma, um incentivo para que ocorram ilegalidades na esfera da adoção" (WEBER, 2010 p.63).

Para agilizar os processos de adoção foi criado O Cadastro Nacional de Adoção (CNA). Trata-se de um sistema único para cadastro de todas as crianças e adolescentes acolhidos institucionalmente, que permite a qualquer juiz realizar uma consulta de pretendentes habilitados e crianças para adoção. Atua como uma ferramenta para o mapeamento dessas informações de forma unificada. Esse sistema encontra-se no ar desde meados de 2009 (OLIVEIRA, 2014).

A seguir as etapas percorridas pelos adotantes entre os meios legais para adoção descrita por Oliveira (2014, p. 47): 
$\mathrm{O}$ (s) pretendente (s) deve dirigir-se a Vara da Infância e da Juventude e procurar o setor técnico, que fará uma primeira reunião explicativa (em geral na mesma hora), [...] é entregue um formulário para cadastro junto Vara [...] cópia do documento de identidade, comprovante de residência, comprovante de rendimentos, declaração médica de saúde física e mental e fotos da casa e da família extensa dos pretendentes [...] apresentação de certidão de distribuição dos cartórios cíveis e criminais [...] é agendado pelo setor técnico duas entrevistas, a primeira com setor psicológico [...] a segunda com assistente social em geral na casa dos pretendentes [...] é agendado o comparecimento ao Curso de Pretendentes a Adoção [...] Ministério Público emitirá, com base nos relatórios, parecer favorável ou desfavorável à habilitação [...] são delimitadas as características da criança ou do adolescente pretendido, finalizando o processo habilitatório.

No entanto, todo o processo jurídico para adoção é considerado "lento e burocrático" pela maioria dos adotantes. (WEBER, 2010, p .62).

Com esse tipo de pensamento e para burlar esta burocracia muitos, fazem a opção pela adoção que os juristas de vários países chamam de adoção 'a brasileira'. Essas "adoções ocorrem como se tudo se passasse de forma natural: o casal vai ao cartório e registra a criança como filho biológico" (ABREU, 2002 p.39). Ressalta-se que esse tipo tramite é crime, e não prescreve.

Sobre o assunto disserta Vargas (2013 p.23) ser essa uma prática que "no Brasil existiu, principalmente, marginal aos processos legais, e escapando as estatísticas". Ocorria em 90\% das adoções que se concretizavam no país até 1988, e para defender esses atos utilizavam-se como argumentos o excesso de burocracia impostos pela legislação vigente até 1989.

\subsection{DADOS DE ADOÇÃO NO BRASIL}

De acordo, com o juiz de Direito da Vara da Infância e Juventude de Sorocaba (SP), Gustavo Molon ${ }^{[7]}$ no artigo Evolução histórica da adoção no Brasil, que a exigência de que o adotante não tivesse filhos legítimos ou legitimados comprova que a finalidade primordial da adoção era suprir a vontade de pessoas inférteis e não proteger a criança e garantir seu direito de ser criada em uma família. 
Na reportagem divulgada pelo Globo News, Oliveira (2016) afirma que no Brasil, 29\% das famílias querem adotar somente meninas e quase $70 \%$ não aceitam ficar com os irmãos. São meninos pardos entre 8 e 17 anos com irmão que acabam ficando mais tempo nos abrigos. Outros fatores também são acrescentados como barreiras, limitando mais ainda o perfil exigido pelos adotantes, pois "enquanto $69 \%$ só aceitam crianças sem doenças, mais de $25 \%$ possuem problemas de saúde".

É compreendido que esses problemas de saúde podem ser sequelas oriundas do período embrionário, através do uso de drogas licita e ilícitas da mãe; falta de um acompanhamento médico no pré-natal; doenças hereditárias, acompanhada após o nascimento; negligencias básicas, violências dentre outros.

As péssimas condições de moradia, saúde, e educação levam muitos pais a buscarem, na internação dos filhos em instituições, assegurarem a alimentação e moradia dos mesmos (VARGAS, 2013 p.18). Antes era permitida "a destituição do poder paterno caso os pais estivessem impossibilitado de manter a subsistência de seus filhos", contudo, depois da criação do ECA, "o Estado torna-se responsável pela manutenção de programas oficiais de auxílio para que famílias carentes possam guardar seus filhos"- art.23 (ABREU, 2002 p.28).

Na mesma reportagem Oliveira (2016) mostra um retrato da adoção no Brasil, com mais de 35 mil pessoas estão na fila de adoção e 6.500 crianças e adolescente por uma familiar para adotá-las no Brasil.

De acordo com os dados expostos acima é possível colocar que é desproporcional o número de adotantes, em comparação as crianças aptas para adoção. Essa dicotomia pode esta associada ao perfil exigido pelos adotantes. Deste modo, essa conta numérica nunca irá nivelar, não enquanto se estabelecer critérios fora da realidade das crianças que vivem nos abrigos em relação à faixa etária, pois elas crescem e os critérios dos adotantes não se alteram, os perfis acabam sendo idênticos entre os adotantes. 


\subsection{DADOS DE ADOÇÃO EM FORTALEZA}

Em Fortaleza não é diferente do cadastro nacional, aponta a fila para adoção, sendo esta superior às crianças aptas a adoção, de acordo com matéria de Oliveira (2017) ${ }^{[8]}$ os números de adoção em Fortaleza não batem; perfis de crianças não correspondem aos desejos das pessoas interessadas em adotar.

A seguir a declaração de Gabriella Pinto, chefe do Cadastro de Adotados de Fortaleza publicada pelo O Globo News Especial.

Quando ${ }^{[9]}$ uma criança chega a um abrigo, ela não pode ser adotada imediatamente. A Justiça antes tenta integrá-la a família biológica. Primeiro aos pais, mas se não for possível a outro parente. Tudo isso deve durar até dois anos, que é o tempo previsto por lei para as crianças viverem em um abrigo, mas, na prática, esse prazo nem sempre é possível e muitas acabam crescendo no abrigo. "A gente vai acabar com todos os esforços para que a gente possa ter para que essa criança fique dentro da família biológica, em último caso ela vai ser disponibilizada para adoção" (OLIVEIRA, 2017 p.02).

Acrescentado a essa informação, o fato de haver muitas crianças que vivem em abrigo e não estarem disponíveis à adoção seria pelo fato de possuírem vínculos com a família biológica e estão em processo de ressocialização ao ambiente familiar. Conforme Oliveira (2017, p.70).

[...] das 530 crianças abrigadas em Fortaleza apenas 84 podem ser adotadas. Contudo, a maioria delas não estar no perfil desejado pelas 64 famílias que já estão em processo de habilitação para adoção" que seria a fase final de ir ao abrigo e escolher a criança de acordo com o perfil estabelecido, lembrando que na "capital 202 famílias estão cadastradas para adoção.

Isso ocorre por que "em geral o perfil adotivo restringe a idade aos primeiros anos de vida, impossibilitando a criança mais velha e ao adolescente a chance de serem adotados", enfim optando na maioria das vezes por bebês (OLIVEIRA, 2014 p.72). 


\subsection{ABRIGO TIA JÚLIA}

Os abrigos, que são os orfanatos, educandários e casas-lares, têm a responsabilidade de zelar pela integridade física e emocional das crianças e adolescentes que passaram por uma situação de abandono social ou pela negligência de seus responsáveis (SILVA e AQUINO, 2005).

O abrigo é a medida provisória excepcional, utilizável como forma de transição para a colocação em família substituta, não implicando privação de liberdade (BRASIL, 2005).

De maneira resumida tendo com subsídio os escritos de Ferreira (2014) repassa-se a seguir um pouco da historicidade do Abrigo Tia Júlia. Conhecido como "A Creche Tia Júlia", foi inaugurada em 06 de fevereiro de 1975 pela primeira dama do país, Lucy Geisel, e pela primeira dama do Estado, Marieta Cals, com capacidade para 100 crianças. Está sob a responsabilidade do Estado do Ceará, sendo sua gestão da competência da Secretaria de Trabalho e Desenvolvimento Social do Estado, inserida nas ações da Coordenadoria de Proteção Social e Especial.

O nome do Abrigo Tia Júlia é uma homenagem do movimento de Promoção Social a uma de suas fundadoras, Júlia Giffone. O fundador da Instituição foi o Governador Cesar Cals, dando a Instituição o nome de "Casa da Tia Júlia", por reconhecimento ao trabalho realizado junto à Assistência Social. Funcionou nessa mesma época o regime de semi-internato, que oportunizou as mães ingressar no mercado de trabalho. Júlia Giffone nasceu em Acaraú, assistente social, morreu vítima de um acidente automobilístico em 1972. Sua vida foi inteiramente dedicada à assistência social, principalmente durante a seca de 1958. Na época dirigia, em Fortaleza, a extinta Hospedaria Getúlio Vargas (FERREIRA, 2014).

Em outubro de 1994 foi reinaugurada na categoria de abrigo, como medida de proteção, atendendo às exigências do Estatuto da Criança e do Adolescente - ECA em uma nova gestão, no governo de Francisco Paula Rocha Aguiar, passando a ser 
chamada de Abrigo Tia Júlia, adotando o regime de internato com 1.500 metros de área construída.

Abrigos (do tipo convencional) são instituições para crianças e adolescentes em situação de risco pessoal ou social, nas quais eles moram e são cuidados por funcionários que exercem a função de monitores ou educadores, sendo responsáveis por suprir as necessidades básicas de alimentação, higiene, saúde, educação, afeto e organização da rotina diária das crianças. Esses monitores ou educadores trabalham em sistema de turno, havendo trocas de funcionários ao longo do dia. [...] podendo chegar a abrigar até duzentas. [...] Quanto a espaço físico, os dormitórios são coletivos, [...] bem como outras dependências como banheiros, salas de uso comum, refeitório, área livre e espaços administrativos (PRADA, 2007, p.22).

Atuando na manutenção de vínculo familiar, o abrigo é uma unidade que tem por objetivo atender integralmente crianças, de ambos os sexos, que se encontra em situação de risco pessoal e social, na condição de abandono ou temporariamente impossibilitadas de permanecer com a família, enquanto são tomadas medidas de retorno ao lar ou de possível adoção. A maioria delas se encontra em situação de manutenção de vínculos, vítima de abandono, violência doméstica incluídos os casos de violência física e psicológica, negligência ou que os pais são dependentes químicos ou estão presos e outra para adoção. Todas essas crianças são oriundas da capital Fortaleza e interior do Estado do Ceará, na condição de abandono ou temporariamente impossibilitadas de permanecer com suas famílias (FERREIRA, 2014).

A maioria das crianças são encaminhadas para o Abrigo através do Conselho Tutelar ou Juizado da Infância e da Juventude. A instituição acolhedora tem como política geral realizar um trabalho de promoção humana, mediante a mobilização de recursos do governo do Estado, com vistas à ampliação da assistência à criança e ao adolescente em situação de vulnerabilidade social e pessoal, viabilizando o retorno desses para uma família. (FERREIRA, 2014, p.28).

$O$ acolhimento é feito com crianças de 0 a 7 anos de idade, seu financiamento vem do Governo do Estado do Ceara - FECOP, Tia Julia encontra-se localizado em Fortaleza na rua: Guilherme perdigão n³05- Parangaba. 
Quadro 1: QUADRO TÉCNICO DO ABRIGO TIA JULIA

\begin{tabular}{|l|l|}
\hline ASSISTENTE SOCIAL & 04 \\
\hline ECONOMIA DOMÉSTICA & 02 \\
\hline ENFERMEIRA & 06 \\
\hline FONOAUDIÓLOGA & 01 \\
\hline DENTISTA & 01 \\
\hline MÉDICO & 01 \\
\hline NUTRICIONISTA & 01 \\
\hline PEDAGOGA & 01 \\
\hline PSICOLOGA & 01 \\
\hline FISIOTERAPEUTA & 01 \\
\hline TERAPEUTA OCUPACIONAL & 01 \\
\hline
\end{tabular}

Fonte: FERREIRA (2014, p.24).

\subsubsection{RESULTADO DAS ENTREVISTAS}

A autorização para a realização das entrevistas foi dada pela Secretária do Trabalho e Desenvolvimento Social-STDS, gestão de competência do Abrigo Tia Julia, os encontros foram marcadas com as profissionais a serem entrevistadas, a escolha foi baseado no contato dos profissionais para com as crianças, e a interação de todo os tramites legais no processo da adoção, optei pelas três assistentes sociais e a psicóloga do Abrigo, mas no período do primeiro contato até a conclusão da última entrevista, o Abrigo ainda não tinha ocupado a vaga da psicologia, deste modo, as entrevistas foram concluídas com as três assistentes sociais que vou identificá-las por nomes fictícios de: Esmeralda, safira e Rubi.

Um dos profissionais que tem suas atividades direcionadas ao processo legal de adoção que pode ser aqui caracterizado é o Assistente Social. Quando a criança chega ao Abrigo, o Serviço Social tem o prazo de 24 horas para abrir junto ao Juizado da Infância e da Juventude, um processo administrativo. O Serviço Social é uma das categorias profissionais que está presente desde a fundação do abrigo, em 1972. É responsável pelo atendimento às necessidades das crianças acolhidas, 
zelando pelo cumprimento dos seus direitos em consonância com o ECA; atende e aconselha aos pais e responsáveis das crianças abrigadas, acompanhando o seu desenvolvimento social, incentivando a reintegração familiar dos filhos e mantém relações com órgãos responsáveis pelo cumprimento das leis referentes às crianças (FERREIRA, 2014, p.31).

Nesses encontros totalizando três visitas ao Abrigo foram explicadas e entregues às vias dos termos de consentimento livre e esclarecido, assinados por ambas as partes objetivando assegurar os direitos éticos das informações repassadas nas gravações pelos entrevistados, e esclarecendo o objetivo da pesquisa deu-se início a aplicação do instrumental utilizado para coleta de dados, no caso o formulário semi estruturado, constituído por perguntas abertas e fechadas.

\section{- ESMERALDA}

Esmeralda é Assistente Social do gênero feminino, trabalha há 04 anos na instituição, Esmeralda informa que a maioria dos casos que chega ao Abrigo é maus tratos. As crianças chegam ao Abrigo através do conselho tutelar, vinda do fórum, autorizada pela Vara da Infância, que estabelece o Abrigo de acordo com faixa etária da criança. O Tia Julia tem média de 58 vagas, hoje abrigadas 58 crianças, sendo que 22 são especiais. O abrigo conta com três modalidades de apadrinhamentos: apadrinhamento afetivo, o financeiro, o de serviço. $O$ financeiro ajuda na educação com 22 crianças em escola particulares, 02 estudam no Instituto dos Cegos do Ceara e 01 no Instituto dos Surdos e Mudos. O apadrinhamento de serviço é composto por clínicas que disponibiliza serviço de saúde.

Alguns cuidados devem ser tomados no que diz respeito ao apadrinhamento afetivo, pois algumas vezes o sujeito aceita 0 compromisso de apadrinhar, mas depois não o mantém, o que deixa a criança com o sentimento de tristeza e frustração. Outro cuidado diz respeito à expectativa que a criança cria de que ela poderá ser adotada pelo padrinho e isso na maioria dos casos não ocorre, o que traz sofrimento à criança (SOUSA; PARAVIDINI, 2011, p.42).

A função do Abrigo é ficar com a criança até ela voltar ao retorno família ou até o momento da adoção. Hoje a burocracia jurídica causa uma grande demora no processo da adoção "poderia ser evitado" (como?) toda criança ter o prazo máximos 
de seis meses, do momento que chega ao Abrigo até o retorno familiar ou adoção, assim, as crianças passaria menos tempo institucionalizada, a adoção tardia poderia não ser tão tardia com a diminuição da burocracia judicial. Os motivos dos adotantes para adoção querem ampliar a família ou infertilidade. Normalmente a adoção dura de 30 a 45 dias.

\section{- SAFIRA}

É Assistente Social do gênero feminino, há 01 ano e dois meses trabalha no Abrigo Tia Júlia, a mesmo relata que a negligência e o abandono de incapaz são casos mais frequentes no abrigo. As crianças normalmente são levadas pelo Conselho Tutelar, Safira lembra que algumas vezes foi questionada por algumas crianças de: Quando vai vir uma mãe pra mim? Cadê minha mãe? Ou as crianças fantasiam o abandono da mãe, dizendo que a mãe estar no hospital ou então que a mãe ligou, essa seria uma forma de explicar para a própria criança a ausência da família biológica.

Elas passam mais tempo institucionalizadas do que deveria, isso acontece por vários motivos, de interesse e em seguida desinteresse da família biológica ou ampliada, o prazo " máximo" no abrigo é de 02 anos, o tempo entre a destituição e a adoção depende de cada caso, normalmente não e menos de um ano.

As dificuldades que ocorrem no dia-a-dia do Serviço Social, estar ligada a rede de atendimento (CRAS, CREAS) ${ }^{[10]}$ que não tem suporte suficiente para as demandas que aparece, os carros que existe são poucos, para fazer visitas e as emergências que venham acontecer com as crianças, muitas demandas espontâneas, junto com vários relatórios, visitas de rotinas. O perfil procurado pelos adotantes é de 0-3 anos, meninas, brancas, saudáveis ou doenças tratáveis, esse perfil seria para que possa criar do seu jeito, e uma maior já vem com seus vícios e costumes e querem educar ao seu modo.

Existe muita burocracia por que são muitas etapas, uma delas é o curso de adoção, pois cada temporada é muito longa uma da outra, e sua duração é muito curta, e o que se ver são pretendentes despreparado para adoção, o que faz a espera pela 
adoção ficar muito longa é o perfil dos pretendentes a adoção, hoje existe pouca visibilidade em relação adoção tardia, seria bom estar mais na mídia, ser mais debatido nas escolas.

- RUBI

Rubi é Assistente social, do gênero feminino, trabalha há 03 anos no Abrigo Tia Júlia. Afirma que os casos mais comuns de crianças irem para o Abrigo está vinculado ao abandono, negligência e violência. Já teve situações em que a própria criança normalmente com mais de 04 anos de idade pede de forma espontânea para voltar para casa dela, existe o estranhamento da criança ao Abrigo quando o motivo do acolhimento tiver sido por negligência.

O perfil de crianças mais procurado pelos adotantes são meninas de 0-3 anos de idade. Dentro dos tramites legais há muita burocracia, pois existe todo um passo-apasso. Quando a criança chega ao Tia Júlia, é realizada toda uma investigação, quais os motivos do abandono pela família, motivos da violência, motivos da negligência.

O trabalho da Assistente Social segundo a Rubi é procurar sempre ir à busca de uma manutenção dos vínculos familiares biológicos, se não tiver sucesso partir para a família extensa, não dando certo, será informado via relatório social à $3^{\underline{a}}$ Vara da Infância de Fortaleza e solicitado à suspensão do poder familiar e a destituição do poder familiar, e se mesmo depois da audiência a família não comparecer e confirmar que não quer a guarda da criança, a mesma é inclusa no Cadastro Nacional de Adoção (CNA), e quando isso acontece algumas crianças já estão com mais de 04 anos de idade. A maior dificuldade para adoção tardia relaciona-se ao perfil que acaba sendo um obstáculo quando o adotante opta pela adoção de crianças em idade de 0 a 03 anos de idade, e a demora na fila acaba sendo inevitável. Quando mudam para uma criança grandinha e a conhecem desistem do processo. O perfil dos adotantes normalmente é o casal heterossexual, de classe média ou de classe média alta. 


\section{CONCLUSÃO}

Este estudo trouxe uma compreensão maior do processo da adoção tardia, focalizando os principais pontos para entender as dificuldades da adoção tardia no Abrigo Tia Julia; de como todo esse tramite se mostra bem burocrático, lento, o qual é percebido de forma unânime pelos pretendentes a adoção e pelos profissionais, o qual acaba penalizando as crianças, as mais afetadas por toda essa demora, significando mais tempo institucionalizada.

Com a pesquisa de campo, facilmente identificamos no discurso das assistentes sociais que 0 abandono, negligência, violência são as maiores causas do recebimento de crianças no abrigo e sua longa estadia dentro da instituição, assim, conclui-se nesse trabalho que as dificuldades da adoção tardia no Abrigo Tia Júlia, estar vinculada a burocracia que se mostra vilã no processo de adoção, acompanhada pelo preconceito reproduzida no discurso do senso comum, que leva ao surgimento de um perfil totalmente contrário da realidade dos abrigos, pois a terminologia "tardia" não existe nem dentro do ECA, sua criação vem de um resultando a desinformação que envolve o tema.

Assim, percebe-se a necessidade de uma maior discussão para haver um entendimento das pessoas sobre a importância e o intuito da adoção tardia, isso poderia ocorre com mais debate sobre o tema, em parceria com mídia escrita e televisiva, dessa forma desmistificando o senso comum, colocando de uma forma mais prática, podendo se beneficiar de campanhas de esclarecimento sobre o tema, panfletos, propagandas, dentre outras coisas, tendo assim como foco a transmitir conhecimento acerca do assunto.

O que hoje existe é um grande abafamento sobre o tema, como se suas práticas legais e ilegais não existissem em meio à sociedade, gerando um silêncio significativo envolto ao tema, observa-se a falta de formulações teóricas em trabalhos apresentados que permitam abrir uma discussão técnica a respeito. 
Visto que mesmo com quase 30 anos da aprovação do Estatuto da Criança e do adolescente (ECA), sente-se uma carência de pesquisas cientificas voltada para um atendimento com a criança e o adolescente, apesar de todo o avança científico dos tempos atuais, alguns temas permanecem desinteressantes aos olhos acadêmicos ou são tratados de forma preconceituosa, adoção é um deles, mas que a passos lentos, atualmente existe um empobrecimento de pesquisa na área social.

Apesar do longo tempo da implementação da 'cultura da adoção necessária' pode-se considerar um avanço, já que esse movimento vem de forma positiva em prol da adoção tardia, e em longo prazo espero que essa 'nova moda' tenha êxito, já que na atual realidade o que predomina é um perfil que não condiz como a realidade dos abrigos, como a procura por crianças recém-nascidas, brancas, do sexo feminino, sem doenças, ainda é o que predomina dentro do processo de adoção.

Portanto, essa pesquisa visa contribuir com um estudo de reflexão, pois acredito que mesmo de forma gradativa houve um avança na adoção tardia, depois de concluir as entrevistas sai bem otimista ao ficar ciente de muitas histórias emocionantes que me foi contado das crianças do abrigo, comprovadas pelas fotos que vi. O resultado dessa pesquisa instigou-me a estudar mais sobre a temática, de querer pesquisar a adoção em outros pontos e crescer mais como uma profissional.

\section{REFERÊNCIAS}

ABREU, Domingues. No bico da cegonha: Historia de adoção e da adoção internacional no Brasil. Rio de Janeiro: Relume Dumará,2002.

ARANTES, Esther Maria de Magalhães.Org. Irene Rizzini, Francisco Pilotti. A arte de governar crianças: A história das políticas sociais, da legislação e da assistência à infância no Brasil. 3ªed. Rio de Janeiro: Cortez, 1991.

BANDEIRA, Regina (20 de agosto de 2014) Dados estatísticos do Cadastro Nacional de Adoção estão disponíveis para consulta na internet. Disponível em: conselho nacional de justiça: http://www.cnj.jus.br/noticias/cnj/61934-dados-estatisticos-do- 
cadastro-nacional-de-adocao-estao-disponiveis-para-consulta-na-internet.Acesso em 11 de dezembro 2017.

BECKER, Howard S. Métodos de pesquisa em ciências sociais. Editora: Hucitec, São Paulo, 1999.

BERTHOUD, C.M.E. Filhos do coração. Taubaté: Cabral Editora Universitária, 1997.

BRASIL. Portal. Em 1927, o Brasil ganhou o primeiro código de menores. (08 de julho de 2015). Disponível em: http://www.brasil.gov.br/cidadania-e-justica/2015/07/em1927-o-brasil-ganhou-o-primeiro-codigo-de-menores. Acesso em 24 de novembro de 2016

BRASIL. Lei no 8.069/90 de 13.07.1990. Estatuto da Criança e do Adolescente. Vitória: Vara da Infância e da Juventude de Vitória, Espírito Santo, 2005.

BRASIL. Portal. (08 de julho de 2015). Em 1927, o Brasil ganhou o primeiro código de menores. Disponível em: http://www.brasil.gov.br/cidadania-e-justica/2015/07/em1927-o-brasil-ganhou-o-primeiro-codigo-de-menores. Acesso em 24 de novembro de 2016.

CAMARGO, M. L.; A adoção tardia no Brasil: desafios e perspectivas para o cuidado com crianças e adolescentes. In: SIMPOSIO INTERNACIONAL DO ADOLESCENTE. 2. ed. São Paulo:2005.

CERVO, Amado Luiz. Metodologia científica/ Amado Luiz Cervo, Pedro Alcino Bervian, Roberto da Silva. - 6ª ed. - São Paulo: Pearson Prentice Hall, 2007.

DOMINGUES, Clayton Amaral. Manual de metodologia da pesquisa cientifica / org. Eduardo Borba Neves, Rio de Janeiro, 2007.

FERREIRA, Norma Soely Pinto. Adoção Tardia: uma análise da visão da equipe psicossocial do Abrigo Tia Júlia. 2014. 70folhas. Trabalho de Conclusão de Curso (Monografia) Serviço Social, Faculdade Cearense.CE,2014. 
GONÇALVES, Lêda.(04 de novembro de 2009). 74 crianças estão na fila de adoção em Fortaleza. Disponível em Diário do Nordeste: http://diariodonordeste.verdesmares.com.br/cadernos/cidade/74-criancas-estao-nafila-de-adocao-em-fortaleza-1.545875.Acesso em 07 outubro de 2016.

GIL, Antônio Carlos. Como elaborar projetos de pesquisa/ Antônio Carlos Gil. - 4. ed. - São Paulo: Atlas, 2002.

HAGUETTE, Teresa Maria Frota. Metodologias qualitativas na Sociologia./ Teresa Maria Frota Haguette, 12- ed. Petrópolis, Rio de Janeiro: Vozes, 2010.

LACERDA, Paulo. Código civil brasileiro: do direito das obrigações. $11^{\circ}$. ed.Rio de Janeiro: Jacinto Ribeiro dos Santos,1922.

LEVINZON, Gina Khafif. Adoção. São Paulo: Casa do psicólogo, 2009.

LISBOA, Antônio Marcio J. A primeira infância e as raízes da violência: Propostas para diminuição da violência. Brasília: L.G.E.,2007.

LISBOA, S. Adoção no Estatuto da Criança e do Adolescente (doutrina e jurisprudência). Rio de Janeiro, Forense, 1996.

LOPES, Cinthia Fonseca (org.) II. Cruz, Erivânia Bernardino. Vade Mecum do Serviço Social. 6. ed. Fortaleza: Premius, 2015.

MARCÍLIO, Maria Luiza. História social da criança abandonada. $1^{\underline{a}}$ ed.São Paulo:Hucitec,2006.

MANZINI, Eduardo José. Entrevista semiestruturada: análise de objetivos e roteiros. Programa de Pós-Gradução em Educação, Unesp - Marília, 2004.

MINAYO, Maria Cecília de Souza. Pesquisa social: Teoria, métodos e criatividade.33.ed.Rio de Janeiro:Vozes,2013. 
OLIVEIRA, Aline.( 30 de maio de 2016). Fila de adoção tem 6,5 mil crianças e adolescentes no Brasil. Disponível em Globo News Especial: http://g1.globo.com/globo-news/noticia/2016/05/fila-de-adocao-tem-mais-de-65-milcriancas-e-adolescentes-no-brasil.html.Acesso em 24/ de outubro de 2017.

OLIVEIRA, Hélio Ferraz de. Adoção: Aspectos jurídicos, práticos e efetivos. São Paulo: Mundo jurídico, 2014.

OLIVEIRA, Sara. (05 de abril de 2017). Perfil de crianças não condiz com desejo dos cadastrados para adoção. Disponível https://www.opovo.com.br/jornal/cotidiano/2017/04/perfil-de-criancas-nao-condizcom-desejo-dos-cadastrados-para-adocao.html.Acesso em 01 de novembro de 2017.

OTUKA, L. K.; SCORSOLINI-COMIN, F.; SANTOS, M. A.; Adoção tardia por casal divorciado e com filhos biológicos: novos contextos para a parentalidade. Estud. psicol. (Campinas), Campinas, v. 30, n. 1, mar. 2013.

PAGANINE, Joseane. Adoção: mudar um destino. Revista de audiências públicas do Senado Federal. Ano 4. n.15, maio de 2013. pp. 15-17. Disponível em: https://www.senado.gov.br/noticias/Jornal/emdiscussao/adocao/contexto-da-adocaono-brasil/historia-da-adocao-no-mundo.aspx. Acesso: 24 de novembro de 2016

PRADA, C. G.; WILLIAMS, L. C. A.; WEBER, L. N. D.; Abrigos para crianças vítimas de violência doméstica: funcionamento relatado pelas crianças e pelos dirigentes. Psicol. teor. prat., São Paulo , v. 9, n. 2, dez. 2007.

REICHERT, C.E. A adoção: estudo geral do instituto. Questão a respeito e orientação moderna. Revista dos tribunais, São Paulo 1934.

REPPOLD, C. T.; Aspectos Práticos e Teóricos da Avaliação Psicossocial para Habilitação à Adoção. Violência e Risco na Infância e Adolescência: pesquisa e intervenção. São Paulo: Casa do Psicólogo, 2005. 
SILVA, E. R. A; AQUINO, L. M. C. Os abrigos para crianças e adolescentes e o direito à convivência familiar e comunitária. IPEA - Políticas Sociais Acompanhamento e Análise, p. 186 - 193, 2005.

SOUSA, K. K, PARAVIDINI, J. L. L.; Vínculos entre crianças em situação de acolhimento institucional e visitantes da instituição. Psicol. Cienc. prof., Brasília, v. 31, n. 3, 2011.

VARGAS, Marlizete Maldonado. Adoção tardia: Da família sonhada a família possível. São Paulo: Casa da Psicologia,2013.

WEBER, Lidia Natalia Dobrianskyj. Pais e filhos por adoção no Brasil: Características, expectativas e sentimentos. Curitiba: Juruá, 2010.

\section{APÊNDICE}

- Roteiro de Entrevista

\section{APRESENTAÇÃO DOS PARTICIPANTES}

$1^{\circ} \operatorname{Sexo} \mathrm{F}() \mathrm{M}()$

$2^{\circ}$ Tempo de trabalho no abrigo

$3^{\circ}$ Cargo que exerce na instituição

\section{VISÃO INSTITUCIONAL}

$4^{\circ}$ Quais são os casos de crianças que chega ao abrigo?

$5^{\circ}$ As crianças de forma espontânea pedem para voltar para casa?

$6^{\circ}$ Existe algum estranhamento ou questionamento ao chegar no abrigo?

$7^{\circ}$ Em media qual o período de permanência de uma criança no Tia Júlia? 
$8^{\circ}$ Existe alguma barreira para execução do seu trabalho dentro do Abrigo?

$9^{\circ}$ Qual o perfil de criança mais procurado pelos adotantes, no Abrigo?

\section{ADOÇÃO TARDIA}

$10^{\circ}$ Dentro dos tramites legais há muita burocracia para adoção?

$11^{\circ}$ Qual a sua visão de uma adoção tardia, são crianças rejeitadas, com mais carente afetiva?

$12^{\circ}$ Quais as dificuldades para uma adoção tardia?

$13^{\circ}$ Qual o perfil dos adotantes?

- Termo de consentimento livre e esclarecido

TERMO DE CONSENTIMENTO LIVRE E ESCLARECIDO

$\mathrm{Eu}$

portador do RG. No

da pesquisa intitulada "......................................." desenvolvida pelo (a) acadêmico

(a)/pesquisador(a) — e permito que

obtenha fotografia, filmagem ou gravação de minha pessoa para fins de pesquisa

científica. Tenho conhecimento sobre a pesquisa e seus procedimentos metodológicos

Autorizo que o material e informações obtidas possam ser publicados em aulas, seminários, congressos, palestras ou periódicos científicos. Porém, não deve ser identificado por nome em qualquer uma das vias de publicação ou uso.

As fotografias, filmagens e gravações de voz ficarão sob a propriedade do pesquisador pertinente ao estudo e, sob a guarda dos mesmos.

Local da pesquisa, ........de de 201

Nome completo do pesquisado 


\section{APÊNDICE - REFERÊNCIAS DE NOTA DE RODAPÉ}

3. PAGANINE, Joseane. (Ano 4 maio de 2013). Adoção: mudar um destino. Acesso: 24 de novembro de 2016. Disponível em: https://www.senado.gov.br/noticias/Jornal/emdiscussao/adocao/contexto-da-adocaono-brasil/historia-da-adocao-no-mundo.aspx.

4. PAGANINE, Joseane. (Ano 4-maio de 2013). Adoção: mudar um destino. Acesso: 24 de novembro de 2016 Disponível em: https://www.senado.gov.br/noticias/Jornal/emdiscussao/adocao/contexto-da-adocaono-brasil/historia-da-adocao-no-mundo.aspx.

5. PAGANINE, Joseane. (Ano 4 - maio de 2013). Adoção: mudar um destino. Acesso: 24 de novembro de 2016. Disponível em: https://www.senado.gov.br/noticias/Jornal/emdiscussao/adocao/contexto-da-adocaono-brasil/historia-da-adocao-no-mundo.aspx

6. GONÇALVES, Lêda. (04 de novembro de 2009). 74 crianças estão na fila de adoção em Fortaleza. Acesso em 07 outubro de 2016. Disponível em Diário do Nordeste: http://diariodonordeste.verdesmares.com.br/cadernos/cidade/74-criancas-estao-nafila-de-adocao-em-fortaleza-1.545875.Acess Acesso em 07 outubro de 2016.

7. GOLÇALVES, Lêda. (04 de novembro de 2009). 74 crianças estão na fila de adoção em Fortaleza. Acesso em 07 outubro de 2016. Disponível em Diário do Nordeste: http://diariodonordeste.verdesmares.com.br/cadernos/cidade/74-criancas-estao-nafila-de-adocao-em-fortaleza-1.545875.

8. OLIVEIRA Sara. (05 de abril de 2017). Perfil de crianças não condiz com desejo dos cadastrados para adoção -O Povo. Disponível em: https://www.opovo.com.br/jornal/cotidiano/2017/04/perfil-de-criancas-nao-condizcom-desejo-dos-cadastrados-para-adocao.html.Acesso em 01 de novembro de 2017.

9. OLIVEIRA, Aline. (30 de maio de 2016). Fila de adoção tem 6,5 mil crianças e adolescentes no Brasil. Disponível em Globo News Especial: 
http://g1.globo.com/globo-news/noticia/2016/05/fila-de-adocao-tem-mais-de-65-milcriancas-e-adolescentes-no-brasil.html.Acesso em 24/ de outubro de 2017.

10. Cento de Referência da Assistência Social - CRAS. Centro de Referência Especializado de Assistência Social - CREAS.

Enviado: Maio, 2018.

Aprovado: Setembro, 2019. 